\title{
Scientific and Methodological Support of Professional Education of a Life Safety Teacher
}

\author{
Marina Kartavykh $^{1}$, Galina Kamerilova ${ }^{1}$, Elena Ageeva ${ }^{1}$, Marina Gubareva ${ }^{1},{ }^{*}$ Irina \\ Prokhorova $^{1}$
}

\author{
${ }^{1}$ Minin Nizhny Novgorod State Pedagogical University, Russia \\ *Email: veryaskina_ma@mail.ru
}

\begin{abstract}
The article is devoted to the consideration of the actual pedagogical phenomenon-scientific and methodological support of professional education of life safety teachers. In the context of modern pedagogical approaches, the considered scientific and methodological support includes scientific and methodological components. The scientific component is represented by a cyclic model of professional education of a teacher of life safety, developed based o the ideas of the cyclical nature of the educational process, the methodology of competence, contextual, technological, situational approaches and the principles of cultural studies, standardization, integration of fundamental and problematic, reflexivity, correlated with the structure of the model itself. The model structure includes the purpose, content, process, and diagnostic results. Each component is considered in detail in the work. The phase logic of deployment of professional education of a teacher of life safety draws attention to itself. The organizational and technological features of the initiative, profile-subject, profile-methodical and reflexive-diagnostic phases of the cyclic model are substantiated and characterized. Attention is drawn to the diversity and hierarchy of the cyclic model of professional education of teachers of life safety and the application of the "matryoshka" principle, since the cyclic model includes a number of cycles of different scales. The methodological block of scientific and methodological support of professional education of teachers of life safety is represented by a massive "portfolio" of educational and methodological documentation.
\end{abstract}

Keywords: Scientific and methodological support, Life safety, Cyclic model, Phase logic, Professional competence, Professional education.

\section{INTRODUCTION}

Fundamental qualitative changes in the system of higher pedagogical education required a revision of its performance-oriented focuses in the competence format, updating the scientific content, and increasing attention to its procedural and technological aspects. Traditional educational and methodological complexes, which were a necessary condition for ensuring the professional training of the future teacher of life safety, are losing their positions, bringing to the fore a new topical pedagogical phenomenon - scientific and methodological support. In modern psychological and pedagogical researches, scientific and methodological support is considered as a process of creating organizational, pedagogical and methodological mechanisms for the practical use of scientific results in educational practice (R.Kh. Gilmeeva, I.N. Ishimova, L.Yu. Mukhametzyanova, F.Sh. Mukhametzyanova, L.Yu. Nazarova, G.K. Serikov, V.I. Sopin, L.P. Tikhonova, N.G. Khabarova, G.A. Shaikhutdinova). Among the private-didactic works devoted to the consideration of scientific and methodological support of professional and pedagogical education in the field of life safety, we should note the research of S.V. Abramova, S.V. Alekseev, E.N. Boyarov, G.S. Kamerilova, M.A. Kartavykh, A.A. Mikhailov, L.A. Mikhailov, V.P. Solomin, P.V. Stankevich. At the same time, the designated pedagogical problems have not yet received a holistic consideration. This fact actualized the problem of this study, which involves the design, theoretical justification and practical 
implementation of scientific and methodological support for professional education of teachers of life safety in all its structural and functional completeness.

\section{RESEARCH METHODOLOGY}

The problem under consideration was solved on the basis of the methodology of cyclicity of the educational process with the use of basic provisions of competence, technological, contextual and situational approaches. The logic of pedagogical design and implementation of scientific and methodological support of professional education included the application of methods of analysis, conceptualization, design and replication of new educational practices in the context of professionalpedagogical education in the field of safety with the wide use of electronic-educational environment.

\section{RESULTS}

The analysis of educational practice showed that only the thesis research of S.V. Abramova made an attempt to conduct a comprehensive approach to solving this issue, in other studies, scientific priority was given to the consideration of certain aspects of professional education of a teacher in the field of life safety [1]. Thus, E.N. Boyarov reveals the features of training bachelor teachers to safe information and environmental activities; A.A. Mikhailov draws attention to the role of network interaction with law enforcement ministries in the process of professional training of teachers of life safety; N.P. Abaskalova and L.A. Akimova focuse on the process of forming a culture of health and safety of life among students; L.A. Mikhailov, V.P. Solomin, P.V. Stankevich [2] reveal the scientific foundations of life safety, paying special attention to the dangers and risks of the social sphere.

This paper proposes a scientific and methodological support for professional education of life safety teachers, reflecting the scientific and pedagogical results of the researches conducted to improve the educational process (I.N. Ishimova, G.K. Panevina) and their implementation in the practice of teaching [3]. Scientific and methodological support integrates scientific and methodological components in its structure [4]. The scientific component of the considered pedagogical phenomenon includes a set of results of academic and applied pedagogical research aimed at improving the educational process and their practical implementation in the context of professional socialization, professional training and personal and professional development of the future teacher of life safety. The methodological block represents the above-mentioned updated educational and methodological complexes, the structure and content of which is a response to modern challenges of the professional and educational environment from the society. A set of educational and methodological documentation has been created that is necessary and sufficient for high-quality professional education of a teacher of life safety, including curricula, schedules, programs, specific teaching methods and technologies that contain system characteristics of the educational process.

The scientific component of the scientific and methodological support of professional education of teachers of life safety was designed based on the pedagogical ideas of the cyclical nature of the educational process (V.S. Bezrukova, M.A. Danilov, L.Ya. Zorina, A.E. Maron, M.A. Kartavykh, N.F. Radionova, A.P. Tryapitsyna, P.I. Pidkasistyj). We would like to emphasize that in the conditions of modernization of higher pedagogical education in the field of life safety, its construction in the format of didactic cycles is characterized by high productivity [5].

A cyclic model of professional education of a teacher of life safety, which formed a scientific component of the considered scientific and methodological support, was developed and implemented in line with the designated ideology. The functioning of the cyclic model is carried out on the basis of methodological provisions of:

- competence-based approach (V.I. Baidenko, A.A. Verbitsky, E.F. Zeer, I.A. Zimniaya, V.A. Kozyrev, A.K. Markova, N.F. Radionova, Yu.G. Tatur, A.P. Tryapitsyna, A.V. Khutorskoy, L. Botcheva, J. Shih, L. C. Huffman, I. Hutchby, J. Moran - Ellis; L. Wach, Richard E. Boyatzis), which assumes the development of professional competencies by future teachers of life safety $[6,7,8]$, provided for by the federal state educational standards of higher education in the areas of training 44.0.01 / 44.03.05 Pedagogical Education;

- contextual approach (A.A Verbitsky), which provides for the logic of building professional education, reflecting the context and specifics of the professional activity of a teacher of life safety;

- technological approach (M.V. Klarin, G.K. Selevko, A.V. Khutorskoy, E. Aizikovitsh, M. Amit), which provides for the use of various pedagogical technologies [9] in the professional education of life safety teacher;

- situational approach (V.V. Serikov, I.K. Toporov), which allows you to build the educational process in terms of content and technology through a systematic solution of typical and unique pedagogical situations.

The implementation of the cyclic model of professional education of the teacher of life safety is carried out on the basis of the principles of cultural studies, standardization, integration of fundamental and problematic, reflexivity, correlated with the structure of the model itself

In the structure of the cyclic model of professional education of a teacher of life safety, presented in figure 
1, the following components are defined: "purpose", "content", "process", "diagnostics of results".

Scientific and Methodological Support of Professional Education of a Life Safety Teacher

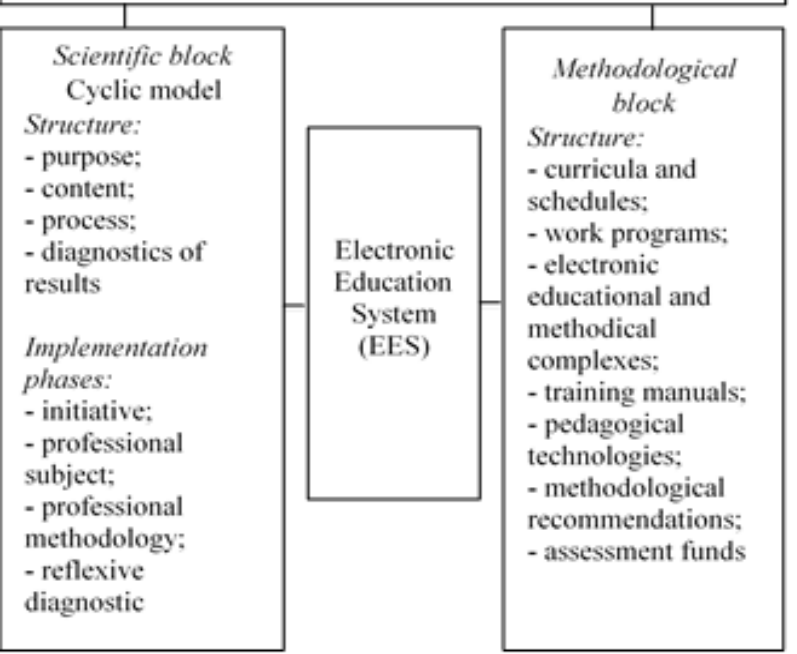

Figure 1 System of scientific and methodological support of professional education of a teacher of life safety.

The component "purpose" sets the vector of movement of a student along his/her competenceoriented trajectory of professional education of a teacher of life safety. It is accompanied by motivational actions aimed at understanding the significance of the chosen profession by students, determining their starting position and professional and pedagogical potential, planning promising strategies for personal and professional development.

The component "content" is represented by axiological, cognitive, praxiological and personal blocks, that corresponds to the features of professional competence [10]. The axiological block of content has a pronounced value component. The basis of the axiological block comprises the key social values: people, health, life, safety. The cognitive block of the content of the cyclic model is represented by a complex of theoretical and empirical knowledge of a subjectmethodical nature, necessary and sufficient for professional education of a teacher of life safety, reflecting the current level of development of science and educational practice. The thesaurus of the cognitive block consists of such basic concepts as "life safety", "danger", "safety", "dangerous situation", "emergency situation", "teaching methods", "educational technologies".

The praxiological block of the content of the cyclic model implies the acquisition by students the methods of pedagogical activity of a teacher of life safety in the process of solving situational problems of analytical, evaluative, predictive, and design type. The personal block of content is associated with the development of the necessary personal qualities of a teacher of life safety in pedagogical activity: purposefulness, initiative, communication skills, love and respect for children, citizenship, organizational skills [11].

The component "process" is the title element in the model structure and demonstrates its cyclical nature and phase logic. In the procedural plan, the cycle of professional education of a teacher of life safety includes four phases: initiative, profile-subject, profilemethodical, reflexive-diagnostic. Their consistent passage is aimed at the final educational result in the form of professional competence.

The component "diagnostics of results" of the cyclic model of professional education of a teacher of life safety is associated with its reflexive-diagnostic phase and is implemented during the final state certification and implies an assessment and determination of the level of professional competence of the graduate. The characteristics of the optimal, permissible and threshold level of professional competence of the teacher of life safety are determined and justified.

Methodological unit of scientific and methodological support of professional education of the teacher of safety designed in the form of a solid "portfolio" of educationalmethodical documentation: curriculum subjects/modules with the rating plans and evaluation funds; guidelines for the development of disciplines, practices, the preparation of course and graduation papers; electronic educationalmethodical complexes, developed in the informationeducational environment (IEE) Moodle. The methodological part of the scientific and methodological support has a navigational character and focuses on the organization of independent activities of students.

\section{RESULTS DISCUSSION}

The core of the content of professional education of a teacher of life safety, which meets the purpose guidelines, has a modular structure. We have identified and justified four leading content lines, designed in the form of three subject and one methodological modules:

1. Anatomical and physiological module that reveals the relevant features of the structure and functioning of a human body, the development of which is necessary for the teacher of life safety to understand the deep mechanisms of safety and first aid in emergency situations.

2. The module "Life Safety in Emergency Situations", which includes a detailed consideration of natural, manmade, social hazards that acquire the nature of emergency situations and the development of methods of safe behavior in the designated conditions.

3. The module "Life Safety in Everyday Life", which provides for the development of issues related to ensuring national security and defense of the state, preventing extremism and terrorism, addictions, ensuring safety on 
the road and in public transport, ensuring safety in an urbanized environment, in terms of tourist trips and hikes.

4. Generalizing normative and methodological module with an applied professional and pedagogical dominant. This module is focused on the refraction of the subject content of life safety through the prism of the organization of training of schoolchildren. This module considers the features of the methodology for teaching life safety, the use of innovative pedagogical technologies, the regulatory framework for life safety and the protection of children's health in the educational process.

The educational process, organized in the form of a cycle of professional education of a teacher of life safety, consists of four phases: initiative, profile-subject, profilemethodical, reflexive-diagnostic. The initiative phase is focused on the "entry" of students into the profession of a teacher of life safety, consideration of the essential characteristics and features of professional activity. It is associated with the development of the academic discipline "Strategies of Personal and Professional Development". The profile-subject phase provides for a pronounced dominant of subject training in life safety, corresponds to the development of the anatomical and physiological module and the modules "Life Safety in Emergency Situations", "Life Safety in Everyday Life". The profile-subject phase is aimed at mastering the fundamental content in the form of well-known algorithms for safe behavior and solving security problems in non-standard situations. The profilemethodical phase is connected with mastering and studying the standard-methodical module and passing of pedagogical practice where methodical preparation with priority of project activity of students prevails. They have to solve specific situational tasks that involve the preparation of methodological developments of life safety lessons and extracurricular activities, the content and technological support of which corresponds to the current level of development of pedagogical science and practice, as well as social needs. The reflexive-diagnostic phase implies understanding and assessment of the future teachers of life safety of the results of professional education and corresponds to the state final certification in the time interval.

Let us pay attention to the diversity and hierarchy of the cyclic model of professional education of the teacher of life safety. In this context, the "matryoshka" principle is applicable, since the cyclic model includes a number of cycles of different scales:

- cycles of the first order-professional education of a teacher of life safety at the level of bachelor's, master's, advanced training and professional retraining;

- second-order cycles correspond to the abovementioned subject-methodical modules;
- cycles of the third order are separate academic disciplines and practices in the structure of professional education of teachers of life safety;

- fourth-order cycles are separate training sessions.

Minin Nizhny Novgorod State Pedagogical University has been developing, improving and implementing the presented scientific and methodological support of professional education of teachers of life safety for two decades. Some aspects of the collective research were reflected in thesis papers of authors, speeches at scientific and practical conferences of various levels and meetings of educational and methodological associations and commissions.

\section{CONCLUSIONS}

Modern challenges form new ideas about the training of teachers of life safety, associated with the creation of conditions for productive learning. Scientific and methodological support for professional education of teachers of life safety developed based on leading approaches combines a cyclic model that embodies conceptual ideas, and methodological content in the form of a "portfolio" of necessary educational and methodological documentation. The innovativeness of the theoretical justification of scientific and methodological support, consisting in the competence orientation and detailed study of the structure of the cyclic model and its phase logic, created the fundamental basis for the successful implementation of the cycle in educational practice. The selected modules of the educational content associated with the educational process and its phases allowed us to systematize the general idea of the planned learning outcomes. Longterm positive results of the work of the authors' team at the Minin Nizhny Novgorod State Pedagogical University allow us to conclude that the selected theoretical and methodological foundations and practical recommendations are appropriate.

\section{ACKNOWLEDGMENTS}

The authors express their gratitude to colleagues from Russian universities that implement programs for training teachers of life safety for their constructive suggestions, which made it possible to improve the scientific and methodological support under consideration.

\section{REFERENCES}

[1] S.V. Abramova, E.N. Boyarov, Methodological Bases of Training of a Specialist of Education in the Field of Life Safety, Modern Problems of Science and Education 6 (2011) 158 
[2] P.V. Stankevich, S.V. Abramova, E.N. Boyarov, Teaching the Discipline «Life Safety» for Students Based on a Modular Approach. Vector of Science of Tolyatti State University, Series: Pedagogy, psychology 3(14) (2013) 246-250.

[3] I.N. Ishimova, Options for Optimizing the Methodological Support of the Educational Process at the University, Bulletin of the South Ural State University, Series "Education, Pedagogical Sciences" Vol. 6 Iss. 3 (2014) 41-47.

[4] M.A. Kartavykh, G.S. Kamerilova, Scientific and Methodological Support of Additional Professional Training Programs for Teaching Staff in the Field of Formation of Children's Skills for Safe Participation in Road Traffic, Vestnik of Minin University Vol. 6 Iss. 1 (2018) 1. DOI: https://doi.org/10.26795/23071281-2018-6-1-3

[5] M.A. Kartavykh, A.A. Basarukina, Cyclicity of Education in the Field of Life Safety, Notes of the Scientist 5(21) (2017) 47-50.

[6] L. Botcheva, J. Shih, L.C. Huffman, Emphasizing Cultural Competence in Evaluation: a ProcessOriented Approach, American Journal of Evaluation Vol. 30 Iss. 2 (2009) 176-188.

[7] Richard E. Boyatzis, The Competent Manager: a Model for Effective Performance, John Wiley \& Sons, 1982, p. 340.

[8] I. Hutchby, J. Moran-Ellis.; L. Wach. Children And Social Competence: Arenas of Action. Falmer press, 1998.

[9] E. Aizikovitsh, M. Amit, Evaluating an Infusion Approach to the Teaching of Critical Thinking Skills Through Mathematics, Procedia Social and Behavioral Sciences 2 (2010) 3818-3822.

[10] S.M. Markova, A.K. Narkoziev. Methods of Research of Professional Education Content. Vestnik of Minin University Vol. 7 Iss. 1 (2019) 1. DOI: https://doi.org/10.26795/2307-1281-2019-7$\underline{1-2}$

[11] E.Yu. Ilaltdinova, A.A. Aladyshkina, "This is the Best Teacher in the World!": the Influence of a School Teacher on the Professional SelfDetermination of Future Teachers. Vestnik of Minin University Vol. 8 Iss. 3 (2020) 1. DOI: https://doi.org/10.26795/2307-1281-2020-8-3-3 